\title{
Delayed splenic abscess after laparoscopic sleeve gastrectomy
}

\author{
Yardesh Singh, ${ }^{1}$ Shamir Cawich, ${ }^{2}$ Imran Aziz, ${ }^{2}$ Vijay Naraynsingh ${ }^{1}$
}

${ }^{1}$ Department of Clinical Surgical Sciences, University of the West Indies, St Augustine, Tobago

${ }^{2}$ Department of Clinical Surgical Sciences, University of the West Indies, St Augustine, Trinidad and Tobago

\section{Correspondence to}

Dr Shamir Cawich, socawich@hotmail.com

Accepted 29 January 2015

\section{SUMMARY}

Splenic abscesses complicating sleeve gastrectomies are extremely rare. We report the fourth recorded case of a splenic abscess; in our case it occurred 10 weeks after sleeve gastrectomy in a 44-year-old man. The clinical presentation was vague but included the triad of fever, left upper quadrant tenderness and leucocytosis. The presence of this triad after sleeve gastrectomy should prompt investigation with contrast $\mathrm{CT}$ scans to exclude a splenic abscess.

\section{BACKGROUND}

Splenic abscesses are uncommon occurrences worldwide. A splenic abscess as a complication of sleeve gastrectomy is extremely rare. To the best of our knowledge, only three cases have been reported to date in the medical literature. ${ }^{1}{ }^{2}$ We report the fourth recorded case of a splenic abscess as a complication of a sleeve gastrectomy.

\section{CASE PRESENTATION}

A 44-year-old man with a body mass index (BMI) of $42 \mathrm{~kg} / \mathrm{m}^{2}$ and no chronic diseases underwent elective laparoscopic sleeve gastrectomy to treat morbid obesity. The operative procedure was uneventful. On day 2, oral intake was started after a contrast swallow revealed that the gastric staple line was intact. The postoperative recovery was uneventful and the patient was discharged on day 4 .

He remained well until 10 weeks later when he experienced fever, malaise, chills and vague colicky abdominal pain. There was no vomiting reported. At this point, his BMI had reduced to $39 \mathrm{~kg} / \mathrm{m}^{2}$. Physical examination revealed that he was feverish at $99.9^{\circ} \mathrm{F}$ and tachycardic at $115 \mathrm{bpm}$. The surgical wounds were completely healed and the abdomen was soft and mildly tender in the left upper quadrant, with no peritonitis.

\section{INVESTIGATIONS}

Laboratory tests revealed leucocytosis at $18000 / \mu \mathrm{L}$ with $86 \%$ neutrophilia. Echocardiogram found no evidence of bacterial endocarditis, HIV serology was negative and hepatitis viral titres were normal.

A contrast CT scan of the abdomen revealed a discrete hypodense cystic mass within the splenic parenchyma, approximately $12 \mathrm{~cm}$ in diameter (figures 1 and 2).

To cite: Singh $Y$, Cawich $S$ Aziz I, et al. BMJ Case Rep Published online: [please include Day Month Year] doi:10.1136/bcr-2014208057

\section{DIFFERENTIAL DIAGNOSIS}

A diagnosis of splenic abscesses was entertained.

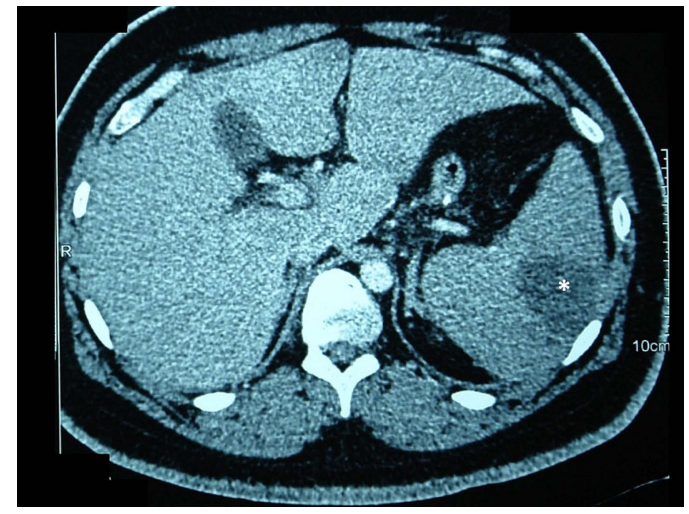

Figure 1 Axial view of a contrast-enhanced CT scan of the abdomen showing a hypodense uniloculated abscess cavity (asterisk) within the spleen.

\section{TREATMENT}

Intravenous fluid resuscitation and broad-spectrum antibiotics were started. Before percutaneous drainage could be organised, the patient reported worsened abdominal pain. This was accompanied by transient hypotension and tachycardia that responded to crystalloid resuscitation. Haemoglobin levels fell from 10 to $6.5 \mathrm{~g} / \mathrm{dL}$ over $5 \mathrm{~h}$. This prompted our decision for emergent splenectomy.

At laparotomy, there was an abscess cavity within the spleen extending from the hilum to the convex surface. The abscess was separate from the gastric staple line and it had ruptured onto the diaphragmatic surface of the spleen causing significant intraperitoneal haemorrhage (figure 3). An open splenectomy was deemed necessary to prevent exsanguinating haemorrhage and it was completed

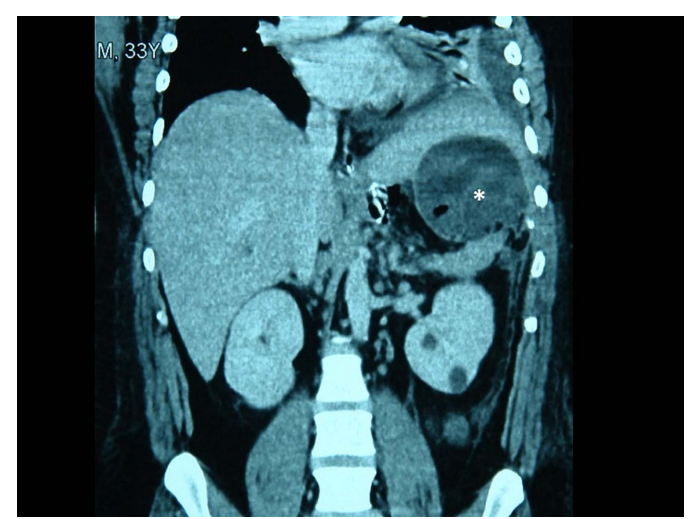

Figure 2 Reconstructed coronal views of a contrastenhanced CT scan of the abdomen showing a hypodense uniloculated abscess cavity (asterisk) within the spleen. 


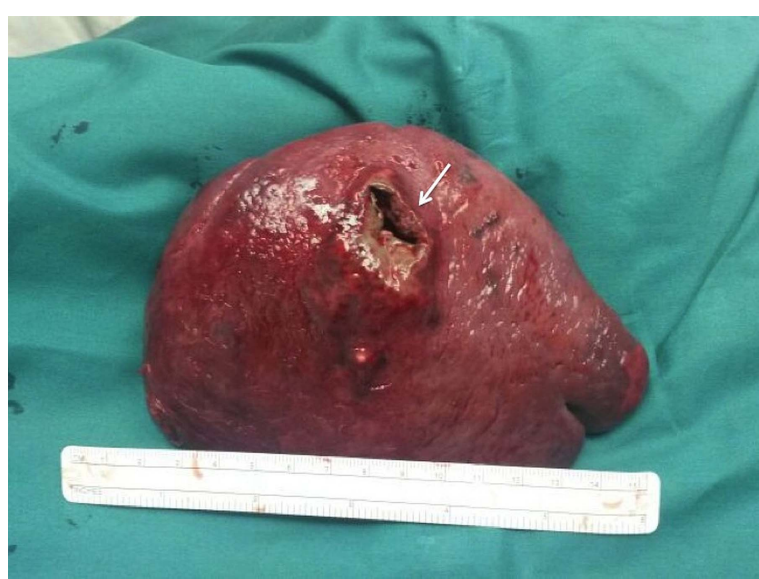

Figure 3 Operative specimen. The abscess cavity has ruptured leaving a rent on the diaphragmatic surface of the spleen (arrows).

uneventfully. The gastric staple line was intact and there was no evidence of a leak.

Cultures from the abscess cavity grew Klebsiella pneumonia, Streptococcus pneumonia and Acinetobacter spp that were all sensitive to carbapenem. Despite culture-directed antibiotics, however, there was persistent fever and leucocytosis. A CT scan of the abdomen/pelvis demonstrated a remnant left upper quadrant collection of gas and fluid that was successfully drained under image guidance.

\section{OUTCOME AND FOLLOW-UP}

The patient had a stormy postoperative course in the intensive care unit, requiring antibiotics and parenteral nutrition. An upper gastrointestinal endoscopy was performed and confirmed the absence of a delayed gastric staple-line leak. Staple line integrity and the absence of a stenosis were confirmed by a contrast study prior to restarting oral intake. The patient spent 3 weeks in hospital and was eventually discharged without event.

\section{DISCUSSION}

A sleeve gastrectomy is a common operation to treat morbid obesity. This operation is usually performed via the laparoscopic approach because it brings numerous advantages in obese patients, including reduced wound complications, faster recovery and unparalleled visibility. In a laparoscopic sleeve gastrectomy, the greater curvature of the stomach is resected, usually over a $36-40 \mathrm{Fr}$ bougie, leaving the pylorus and gastrooesophageal junction intact. A necessary step is dividing the gastrosplenic ligament to mobilise the stomach. Although short gastric arteries are sacrificed, the splenic artery is left intact to ensure perfusion to the spleen.

The stomach is transformed into a narrow tubular channel to produce weight loss by two means: mechanical restriction of gastric distension and removal of fundal P/D1 cells that secrete ghrelin-a hormone that stimulates hunger. ${ }^{3}$ Compared with a gastric bypass, sleeve gastrectomy is a safer option in high-risk patients because the duration of operation is shorter and it avoids the potential complications of a gastrojejunal anastomosis. ${ }^{3}$ It also avoids the use of implantable devices as in gastric banding. ${ }^{3}$

There are many recognised complications of sleeve gastrectomy, including staple-line leaks, intra-abdominal infections and mechanical obstruction from strictures. A splenic abscess is not yet a recognised complication. This is now the fourth reported case of a splenic abscess, despite the presence of large series and systematic reviews with thousands of sleeve gastrectomies. ${ }^{4-10}$

There have only been three prior reports of splenic abscesses occurring after sleeve gastrectomies in a 19 -year-old man, ${ }^{1}$ a 35 -year-old woman ${ }^{2}$ and a 36-year-old woman, ${ }^{2}$ all without medical comorbidities. In all three cases, uneventful operative procedures were reported and the patients were discharged from hospital tolerating diet. They returned after a delay that ranged from $16^{1}$ to 75 days. $^{2}$ Our patient followed this pattern. He was a young adult without comorbidities and developed the splenic abscess 10 weeks after an uncomplicated operation. A bariatric surgeon reviewed the archive of our operation and could not identify any deviation from standard operative technique or any point of iatrogenic splenic injury.

In most patients with a splenic abscess not related to sleeve gastrectomies, one or more recognised risk factors ${ }^{2}{ }^{11-13}$ can be identified: an insult that devitalises the spleen (trauma, iatrogenic injury, sickle-cell disease), a source of embolic infection (generalised sepsis, infective endocarditis, intravenous drug use), some form of immune compromise (HIV, diabetes, malignancy) or a haematological disorder. These predisposing conditions were absent from all four cases after sleeve gastrectomy, ${ }^{12}$ suggesting that another aetiology is responsible.

Four prevailing theories have been proposed in the bariatric population. The first is that a splenic abscess may occur as a result of direct extension from a gastric staple-line leak. Leaks occur after $1.2^{3}-2.4 \%{ }^{4}$ of sleeve gastrectomies and can rise to as high as $20 \%$ after repeat operations. ${ }^{14-16}$ When Aurora et al ${ }^{4}$ evaluated the incidence of leaks in a meta-analysis of 4888 sleeve gastrectomies from 29 studies, they reported that 50\% occurred more than 10 days after operation. Such a delay allows ample time for the infective process to extend into a devitalised spleen creating an abscess cavity. In our case, however, a leak was not identified on contrast study, endoscopy or at surgery.

The second theory holds that there is iatrogenic splenic injury at the time of surgery, resulting in devitalisation and subsequent colonisation. However, the operative procedure was reported to be uneventful in all three cases previously reported ${ }^{1} 2$ and we could not identify any point of iatrogenic splenic injury in our case.

The third theory is that inadvertent splenic ischaemia occurs after sleeve gastrectomy. Although the left gastroepiploic and short gastric vessels are deliberately ligated in this procedure, stomach viability is ensured by arterial supply through the left gastric artery and the spleen via the splenic artery. However, Perez et al ${ }^{17}$ demonstrated that arterial flow in the left gastric artery was disturbed in $55 \%$ of uneventful cases through a yet undetermined mechanism, predisposing the gastric remnant to ischaemia and delayed staple-line leaks. A similar process may occur at the nearby splenic artery, leading to splenic ischaemia and infarction as a prelude to abscess formation. Stamou et $a l^{18}$ provided supporting evidence when they deliberately observed the spleen before deflation of the pneumoperitoneum at the end of 287 sleeve gastrectomies. They reported that splenic ischaemia (as evidenced by arterial demarcation on inspection and confirmed by postoperative Doppler ultrasound) occurred in $4 \%$ of cases. Although in over 95\% of cases splenic ischaemia did not become clinically evident, it could be a predisposing factor in susceptible patients.

Finally, Sakran et $a l^{2}$ theorised that temporary immune suppression in the immediate postoperative period associated with rapid weight loss and limited oral intake could be responsible for the formation of the abscess in a partially infarcted spleen from a transient bacteraemia.

In this case, we entertained the possibility that the abscess was a complication of the sleeve gastrectomy since there was a 
temporal relationship with the operation that mirrored the previously reported cases. ${ }^{1}{ }^{2}$ In this case, however, there was no gastric staple-line leak or iatrogenic splenic injury.

An additional mechanism should be entertained. We theorised that transient bacteraemia occurred when the stapler breached the gastric mucosa. This led to retrograde transmission of microbes through the gastric vasa brevia across the gastrosplenic omentum to the spleen. When retrograde transmission is combined with splenic ischaemia as postulated by Stamou et al ${ }^{18}$ and potentiated by temporary immune suppression as theorised by Sakran et al, ${ }^{2}$ the stage is set for splenic abscesses to occur.

In all cases, the presentation is usually vague because an obese abdomen can mask physical signs. Our patient presented with vague left upper quadrant pain, fever and leucocytosis. Two patients in the existing reports presented with a similar triad. ${ }^{2}$ Excluding the third reported case where the patient presented with multiple organ failure from advanced sepsis, this triad may herald a splenic abscess after sleeve gastrectomy.

In all reported cases, the diagnosis has been made on contrast-enhanced CT scanning. ${ }^{1}{ }^{2}$ This is a sensitive modality to diagnose splenic abscesses. The abscess cavity usually appears as a low-density lesion, often with a peripheral enhancing rim of inflammatory tissue. Although CT scan remains the gold standard for diagnosis, ${ }^{2}{ }^{13}$ ultrasound can also demonstrate the characteristics of splenic abscess. ${ }^{2}$ Both of these imaging studies have a sensitivity of $98 \% .^{2} 1920$

Splenic abscesses should be treated with broad-spectrum antibiotics because they tend to be polymicrobial. ${ }^{2} 2021$ In this case and the three previously reported after sleeve gastrectomy, enteric Gram-negative and Gram-positive bacteria were the commonest organisms. ${ }^{1}{ }^{2}$ Although splenectomy is recognised as definitive management, ${ }^{19-21}$ treatment for solitary abscesses has shifted towards percutaneous or laparoscopic drainage in order to preserve the spleen. ${ }^{2} 22$ Splenectomy was required in our case and in two of the three reported cases after these minimally invasive options failed.

\section{Learning points}

- Although rare, bariatric surgeons should be aware of splenic abscess as a potential complication of laparoscopic sleeve gastrectomies.

- The clinical picture is usually non-specific because the signs are easily masked in an obese abdomen.

- The triad of fever, left upper quadrant pain and leucocytosis may herald a splenic abscess post-sleeve gastrectomy.

- Patients who develop this triad should be investigated with contrast-enhanced CT scan to exclude splenic abscesses.
Competing interests None.

Patient consent Obtained.

Provenance and peer review Not commissioned; externally peer reviewed.

\section{REFERENCES}

1 Avulov V, McQuillen DP, Mizusawa M, et al. Splenic abscess after sleeve gastrectomy. SAGES Metab Obes Arch 2014;7:71.

2 Sakran N, lliviitzki A, Zeina AR, et al. Splenic abscess after sleeve gastrectomy: a report of two cases. Obes Facts 2012;5:635-9.

3 Frezza EE. Laparoscopic vertical sleeve gastrectomy for morbid obesity. The future procedure of choice? Surg Today 2007;37:275-81.

4 Aurora AR, Khaitan L, Saber AA. Sleeve gastrectomy and the risk of a leak: a systematic analysis of 4,888 patients. Surg Endosc 2012;26:1509-15.

5 Parikh M, Issa R, McCrillis A, et al. Surgical strategies that may decrease leak after laparoscopic sleeve gastrectomy: a systematic review and meta-analysis of 9991 cases. Ann Surg 2013;257:231-7.

6 Colquitt JL, Picket K, Loveman E, et al. Surgery for weight loss in adults. Cochrane Database Syst Rev 2014;(8):CD003641.

7 Chang SH, Stoll CR, Song J, et al. The effectiveness and risks of bariatric surgery: an updated systematic review and meta-analysis, 2003-2012. JAMA Surg 2014; 149:275-87.

8 Li JF, Lai DD, Ni B, et al. Comparison of laparoscopic Roux-en-Y gastric bypass with laparoscopic sleeve gastrectomy for morbid obesity or type 2 diabetes mellitus: a meta-analysis of randomized controlled trials. Can J Surg 2013;56: E158-64.

9 Yip S, Plank LD, Murphy R. Gastric bypass and sleeve gastrectomy for type 2 diabetes: a systematic review and meta-analysis of outcomes. Obes Surg 2013;23:1994-2003.

10 Padwal R, Klarenbach S, Wiebe N, et al. Bariatric surgery: a systematic review and network meta-analysis of randomized trials. Obes Rev 2011;12:602-21.

11 Ramakrishnan MR, Sarathy TKP, Balu M. Percutaneous drainage of splenic abscess: case report and review of literature. Pediatrics 1987;79:1029-30.

12 Aessopos A, Politou M, Farmakis D, et al. Staphylococcus aureus abscess of the spleen in a beta-thalassemia patient. Scand J Infect Dis 2002;34:466-80.

13 Smyrniotis V, Kehagias D, Voros D, et al. Splenic abscess. An old disease with new interest. Dig Surg 2000;17:354-7.

14 Nocca D, Krawczyowsky D, Bomans B, et al. A prospective multicenter study of 163 sleeve gastrectomies: results at 1 and 2years. Obes Surg 2008;18:560-5.

15 Himpens J, Dapri G, Cadiere GB. A prospective randomized study between laparoscopic gastric banding and laparoscopic isolated sleeve gastrectomy: results after 1 and 3years. Obes Surg 2006:16:1450-6.

16 Fuks D, Verhaeghe P, Brehand 0, et al. Results of laparoscopic sleeve gastrectomy: a prospective study in 135 patients with morbid obesity. Surgery 2009;145:106-13.

17 Perez $M$, Brunaud L, Kedaifa $S$, et al. Does anatomy explain the origin of a leak after sleeve gastrectomy? Obes Surg 2014;24:1717-23.

18 Stamou KM, Menenakos E, Gomatos IP, et al. Clinical implications of sleeve gastrectomy as a source of spleen infarction or ischemia. Obes Surg 2011;21:1490-3.

19 Ooi LL, Nambiar R, Rauff A, et al. Splenic abscess. Aust N Z J Surg 1992;62:780-4.

20 Chang KC, Chuah SK, Changchien CS, et al. Clinical characteristics and prognostic factors of splenic abscess: a review of 67 cases in a single medical center of Taiwan. World J Gastroenterol 2006;12:460-4.

21 Nagem RG, Petroianu A. Subtotal splenectomy for splenic abscess. Can J Surg 2009;52:E91-2.

$22 \mathrm{Ng} \mathrm{KK}$, Lee TY, Wan YL, et al. Splenic abscess: diagnosis and management. Hepatogastroenterology 2002;49:567-71. 


\section{Rare disease}

Copyright 2015 BMJ Publishing Group. All rights reserved. For permission to reuse any of this content visit http://group.bmj.com/group/rights-licensing/permissions.

BMJ Case Report Fellows may re-use this article for personal use and teaching without any further permission.

Become a Fellow of BMJ Case Reports today and you can:

- Submit as many cases as you like

- Enjoy fast sympathetic peer review and rapid publication of accepted articles

- Access all the published articles

- Re-use any of the published material for personal use and teaching without further permission

For information on Institutional Fellowships contact consortiasales@bmjgroup.com

Visit casereports.bmj.com for more articles like this and to become a Fellow 